\title{
JOGO DA VELHA ENVOLVENDO CLIMATOLOGIA E A CIDADE DE SÃO GONÇALO/RJ
}

\author{
Old games involving climatology and the city of São Gonçalo//RJ
}

Juegos antiguos relacionados con la climatología y la ciudad de São Gonçalo // RJ

Lucas da Silva Santos

DGEO-FFP-UERJ

- lucas.silva-santos@outlook.com

\author{
Recebido em 09/10/2019. Aceito para publicação em 20/10/2019. \\ Versão online publicada em 10/11/2019 (http://seer.ufrgs.br/paraonde)
}

\begin{abstract}
Resumo:
O jogo é um recurso importante na mediação do conhecimento escolar, pois ele permite trabalhar cognitivamente com os estudantes a partir dos conceitos e conteúdos desenvolvidos em sala de aula. Desta forma, este trabalho objetivo apresentar com trabalhar o jogo da velha como forma de compreensão sobre o ensino de clima do município de São Gonçalo desenvolvido pelos estudantes da turma do $6^{\circ}$ ano do ensino fundamental do CIEP 041- Vital Brazil, localizada no bairro do Luiz Caçador- SG. A metodologia utilizada fora a pesquisa qualitativa, uma vez que os discentes constituem como indivíduos participativos e autores no processo da construção do conhecimento acerca de clima e os fenômenos climáticos. A mediação foi realizada a partir da elaboração de uma atividade lúdica (o jogo da velha) articulada com o ensino de geografia e cidade. Esta atividade atingiu enquanto resultado conceder a participação e interação dos estudantes, até mesmo daqueles que aparentemente estavam tímidos, no decorrer das aulas anteriores, os quais terminaram contribuindo na dinâmica do jogo. Desse modo, a atividade colaborou para a melhora da relação do ensino-aprendizagem, gerando nos educandos o aprender e participar das aulas de geografia.
\end{abstract}

Palavras-chave: Climatologia, Ensino de Geografia, Jogo lúdico, Cidade.

\begin{abstract}
:
The game is an important resource in the mediation of school knowledge, as it allows to work cognitively with students from the concepts and content developed in the classroom. Thus, this paper aims to present working with the tic-tac-toe as a way of understanding about climate teaching in the municipality of São Gonçalo developed by students of the 6th grade elementary school of CIEP 041- Vital Brazil, located in the neighborhood of Luiz Hunter-SG. The methodology used was the qualitative research, since the students constitute as participative individuals and authors in the process of building knowledge about climate and climate phenomena. The mediation was performed from the elaboration of a playful activity (the tic-tac-toe) articulated with the teaching of geography and the city. This activity achieved as a result the participation and interaction of the students, even those who were apparently shy, during the previous classes, which ended up contributing to the dynamics of the game. Thus, the activity contributed to the improvement of the teaching-learning relationship, generating in the students to learn and participate in geography classes.
\end{abstract}

Key-words:Climatology, Geography Teaching, Play, City.

\section{Resumen:}

El juego es un recurso importante en la mediación del conocimiento escolar, ya que permite trabajar cognitivamente con los estudiantes a partir de los conceptos y contenidos 
desarrollados en el aula. Por lo tanto, este documento tiene como objetivo presentar el trabajo con el tic-tac-toe como una forma de entender la enseñanza del clima en el municipio de São Gonçalo desarrollado por estudiantes de la escuela primaria de sexto grado del CIEP 041- Vital Brasil, ubicado en el barrio de Luiz Hunter-SG. La metodología utilizada fue la investigación cualitativa, ya que los estudiantes se constituyen como individuos y autores participativos en el proceso de construcción de conocimiento sobre el clima y los fenómenos climáticos. La mediación se realizó a partir de la elaboración de una actividad lúdica (el tictac-toe) articulada con la enseñanza de la geografía y la ciudad. Esta actividad logró como resultado la participación e interacción de los estudiantes, incluso aquellos que aparentemente eran tímidos, durante las clases anteriores, lo que terminó contribuyendo a la dinámica del juego. Así, la actividad contribuyó a mejorar la relación enseñanza-aprendizaje, generando estudiantes para aprender y participar en clases de geografía. Palabras-clave:Climatología, Enseñanza de Geografía, Juego, Ciudad

\section{Introdução}

É um desafio constante promover uma aprendizagem que seja significativa para os estudantes, pois requer elaboração de aulas que propiciem atividades lúdicas e contextualizadas. Este é o trabalho docente em construir ou propor diferentes metodologias de ensino quepermitam aos estudantes se reconhecerem como parte do processo da construção do conhecimento - geográfico.

Desta forma, pode-se dizer que ao trazer, os temas cidade e clima busca-se construir conhecimentos que estão para além do livro didático, sendo necessário a mediação do professor.

O estudo da cidade tem como proposta permitir ao estudante a compreensão da espacialidade em sua dimensão multi-escalar, elucidar problemas e auxiliar na compreensão dos distintos aspectos físicos pertencente à cidade. Permitir ao indivíduo que é sujeito/agente, reconhecer-se como participante do processo de produção das espacialidades, isto éparte da reflexão do ensino geográfico adotado, na qual visa à formação de cidadãos com consciência espacial.

No esforço de trazer práticas e técnicas na qual possibilite um aprendizado mais enriquecedor do conteúdo de climatologia, do $6^{\circ}$ ano do ensino fundamental, em relação, ao entendimento do espaço onde está introduzido (na cidade), o lúdico manifesta se enquanto um considerável apetrecho para compreender a teoria (PIAGET, 1975).

Assim, a atividade lúdica, no caso deste texto, os jogos, no ensino de geografia permite o prazer e entretenimento no decorrer de uma aula, à medida que auxilia 0 discente a desenvolver atribuições mental e motora- além da habilidade de atenção e compreensão.

Este trabalho objetivo expor uma proposta marcada na utilização dos jogos lúdicos como maneira de abordar conteúdos da Geografia física, sobretudo nos elementos da climatologia, com ênfase na cidade de São Gonçalo/RJ. O jogo em questão é chamado de "jogo da velha", a escolha desse jogo foi devida por não possuir limite de participantes e, também, decorrente do conhecimento de suas regras em razão da popularidade da brincadeira.

Portanto, o objetivo deste texto é apresentar a realização da atividade mediada em sala de aula, com a aplicação do "jogo da velha", vinculado o conteúdo de climatologia com a cidade de São Gonçalo, trabalhada com estudantes de uma turma de 6o ano do

ParaOnde!?, Porto Alegre, v.12 n.2, p.59-72, 2019.http://seer.ufrgs.br/paraonde Edição Especial - III Colóquio de Pesquisadores em Geografia Física Ensino de Geografia 
ensino fundamental do CIEP 041- Vital Brazil - Luiz Caçador- São Gonçalo/RJ. Esta ação é parte do projeto de pesquisa financiado pela FAPERJ - "Leitura sobre as espacialidades das cidades e suas representações na sala de aula" -, compreendido no período de 2016 a 2018. Tendo em vista, observa-se que a finalidade é estimular o ensino e aprendizagem em geografia por meio de realização de atividades lúdicas.

\section{Desenvolvimento}

\section{A questão do estudo de climatologia na educação básica}

O ensino da geografia física na escola se perpassa em identificar, interpretar e analisar os fenômenos físico-naturais que estão organizados no espaço geográfico. Um dos fenômenos trabalhados em sala de aula e que tem relaçãovisível e sentido é o clima. Desta maneira, compreender este conceito é importante para que o estudante desenvolva os conhecimentos elementares como tempo, fatores e elementos climáticos, problemas ambientais e outros que fazem parte da vida cotidiana em diferentes escalas.

Assim, o discente necessita apoderar se desse conhecimento teórico previamente de estabelecer o vínculo dos ramos do conhecimento, confeccionando desse modo elemento inevitável do processo de ensino de geografia física.

A climatologia trata dos padrões de comportamento da atmosfera em suas interações com as atividades humanas e com a superfície terrestre no decorrer de um período de tempo muito longo (MENDONÇA; DANNI-OLIVEIRA, 2007). No âmbito geográfico, a compreensão do clima está ligada ao entendimento da nossa realidade social e histórica e, por conseguinte, do ambiente no qual vivemos (DENIZART, 2011, p.02).

Destarte, segundo 0 autor, compreender o comportamento atmosférico especializado também possibilita trabalhar as diferentes interações com as atividades humanas bem como as paisagens com a intenção que seja capaz de ler de maneiras efetivas as organizações espaciais. Ademais, para compreender o conceito de paisagem faz se necessário conhecer princípios particulares dos elementos na qual está inserido em nossa sociedade, bem como: aspectos físicos.

A geografia colocada dentro de sala empenha-se em dialogar com a natureza e a sociedade. Dessa maneira, configura-se enquanto relevante o ensino de geografia física, com a finalidade que o educando compreenda meio natural e seu desempenho para captar a ação do indivíduo neste espaço. Assim, é capaz apossar-se de conhecimentos peculiares ao tempo e clima, à geomorfologia, aos recursos hídricos, ao solo e à cobertura vegetal.

A climatologia possui um papel importante na sociedade. Compreende o clima, segundo Ayoade (2010); como um importante elemento do ambiente natural, pois atua diretamente como os processos de formação do relevo, pedologia e desenvolvimento das paisagens terrestres. Fornecendo os principais fatores que permitem a vida da humanidade que são o ar e água; e todos os outros que desencadeiam a partir desses (BARBOSA; OLIVEIRA, 2012, p.111).

O ensino de climatologia atribui-se uma função primordial para a formação do estudante na compreensão de seu espaço. A climatologia é um campo na qual se configura enquanto agente fundamental para a percepção da organização espacial, tendo

ParaOnde!?, Porto Alegre, v.12 n.2, p.59-72, 2019.http://seer.ufrgs.br/paraonde Edição Especial - III Colóquio de Pesquisadores em Geografia Física Ensino de Geografia 
em vista que a dinâmica climatológica está vinculada com o solo, a vegetação, a economia, turismo e entre outros aspectos. Portanto, sua compreensão é de extrema relevância para construir um sujeito conhecedor de seu espaço.

Por essa razão, o conceito de paisagem engloba a climatologia, o espaço vivido e as modificações pelo qual esse espaço tem decorrido ao longo do tempo. Este conceito geográfico abrange distintas perspectivas a respeito de sua definição. Como elucidado abaixo.

[...] tanto a paisagem quanto o espaço resultam de movimentos superficiais, uma realidade de funcionamento unitário, um mosaico de relações, de formas, funções e sentidos [...] paisagem artificial é a paisagem transformada pelo homem, enquanto grosseiramente podemos dizer que a paisagem natural é aquela ainda não moldada pelo esforço humano. Se no passado havia a paisagem natural, hoje essa modalidade praticamente não existe mais. Se um lugar não é fisicamente tocado pela força do homem, ele todavia é objeto de preocupação e intenções econômicas ou políticas, (SANTOS, 1994, p. 64).

O autor estabelece o conceito de paisagem baseado no movimento do sujeito e realidade na qual se encontra nesses espaços. Ocasionando separação entre paisagens alteradas pelo ser humano e a naturais - salientando que essa, na pratica, não existem, visto que quase todo o espaço de alguma maneira foi mexido ou sofre ação direta ou indireta pela humanidade. Em contrapartida, Bertrand (1971) alega que a paisagem é uma combinação instável de elementos físicos, biológicos e antrópicos que reage de forma dialética uns com os outros, fazendo de cada paisagem um espaço único e esses elementos indissociáveis.

Apesar disso, é significativo o debate pertencente as representações sócias na qual os estudantes detêm sobre o conceito de paisagem e o do assunto de climatologia. Conforme Cavalcanti (2012) para lidar com a formação de conceitos dos mesmos é fundamental compreender quais são as representações sociais que o discente estabelece em torno desses conceitos.

Tendo em vista isso, ao começar a trabalhar o ensino de climatologia em sala de aula, a paisagem se torna um elemento primordial para a compreensão do assunto e suas abundantes categorias de paisagens climáticas; sendo referente à do local ou do global são cruciais para esse cunho. Nessa perspectiva, a união do conceito geográfico de paisagem e do assunto climatologia constitui um par essencial para a facilitação do processo de ensino a respeito do clima.

\section{Jogos Lúdicos: sua relação com a cidade e o clima}

Diante do atual cenário da educação pública, notam-se problemas no desenvolvimento do processo de ensino. A supressão de recursos nas escolas e o uso exclusivo do livro didático na construção das aulas geram desinteresse na participação dos estudantes e desmerece os saberes dos mesmos. Dessa maneira, transfigura-se o desafio do educador, promover diferentes modelos de ensino que permitam ao estudante reconhecer-se como parte integrante da realidade.

A procura por mecanismos de ensino na qual auxiliam para o mais adequado entendimento do conteúdo por parte do discente é necessário se fundamentar em

ParaOnde!?, Porto Alegre, v.12 n.2, p.59-72, 2019.http://seer.ufrgs.br/paraonde Edição Especial - III Colóquio de Pesquisadores em Geografia Física Ensino de Geografia 
pesquisas continuas. Constata-se, que o uso de jogos dedicados ao ensino viabiliza o estudante entender dados assuntos.

Conforme Tupy (2013) afeição pelos jogos em sala de aula se explica pela necessidade de materiais atrativos, interessantes que despertam a curiosidade e a vontade de aprender de forma prazerosa. Desse modo, o jogo consegue ser capaz de colaborar para o ensino, como elucida Silva (2006):

[...] o jogo confere ao aluno um papel ativo na construção dos novos conhecimentos, pois permite a interação com o objeto a ser conhecido incentivando a troca de coordenação de idéias e hipóteses diferentes, além de propiciar conflitos, desequilíbrios e a construção de novos conhecimentos fazendo com que o aluno aprenda o fazer, o relacionar, o constatar, o comparar, o construir e o questionar (SILVA, 2006, p. 143).

Nesse sentido, é de extrema relevância considerar as atividades lúdicas enquanto um meio de compreende um conteúdo colocado. Além disso, a utilização de jogo contribuiu como um meio de abranger todos os estudantes no processo da construção do conhecimento- ocasionando os mesmos na vontade de aprender.

Os jogos são ferramentas eficientes para ensinar diversos conteúdos, dentro ou fora de sala, visto que as atividades de cunho lúdico busca atrair a atenção do discente se transformado num relevante mecanismo para o ensino. Quando se lida com a formação de indivíduos é frequente a indagação sobre quais métodos de ensino adotar, e a procura encerra no momento que é revertido a inercia nas aulas, isto é, quando se proporcionam em desenvolver ações dinâmicas na qual colaborem no entendimento do estudante. $O$ docente busca frequentemente estabelecer práticas de ensino para a melhor nortear 0 processo de aprendizagem de acordo com a realidade que o educando está inserido.

O cotidiano é permeado por práticas espaciais, resultado de experiências materiais e imateriais, e vai além do palpável, do que é visto. A produção acontece diariamente pelos indivíduos que nela produzem e são produzidas, as relações sociais se materializam na cidade e dão a ela forma e conteúdo, (SACRAMENTO, MELLO, SANCHES, SILVA, 2016, p. 85).

Assim, é pensar como sua consciência pode modificar a forma de educar geograficamente, como a mediação pode articular a aula, orientando o saber do aluno. Para isso, as concepções didáticas são extremamente importantes para perceber as diferenças forma de ensinar. Pensar a cidade de São Gonçalo como representação das experiências vividas dos estudantes desta cidade é dar significados aos conteúdos originários do Currículo Mínimo (Básico) de geografia da SEEDUC -RJ. Assim,

\begin{abstract}
A cidade de São Gonçalo está representada pelos diferentes elementos que a constituem os homens, as firmas, as instituições, o meio ambiente e a infraestrutura que as modificam conforme sua necessidade de organizá-la. Esta cidade está impregnada das marcas que se expressam pelas relações sociais, pelas ações políticas que a caracterizam com as múltiplas possibilidades de articulação entre dos aspectos físico-naturais e seus impactos sobre as pessoas que vivenciam e caminham nestes lugares. (SACRAMENTO; SOUZA, 2016, p. 19)).
\end{abstract}

Percebe se assim que a aplicação de jogos empregados ao ensino e a cidade viabiliza a compreensão dos conteúdos, constrói seu saber de maneira funcional, dinâmico e eficaz.

ParaOnde!?, Porto Alegre, v.12 n.2, p.59-72, 2019.http://seer.ufrgs.br/paraonde Edição Especial - III Colóquio de Pesquisadores em Geografia Física Ensino de Geografia 


\section{O espaço urbano de São Gonçalo}

O município de São Gonçalo possui uma gênese conturbada, a cidade foi preliminarmente introduzida no ano de 1890, sendo separado do Município de Niterói. Nesse momento está região exercia por um momento de ampla expansão da economia relacionada à produção e instauração de engenhos de cana de açúcar. Por isso a autonomia simboliza as predileções uma aristocracia agraria na qual não se reconhecia representada pelos políticos de Niterói.Em 1892, o município teve sua emancipação desmanchada, sendo São Gonçalo rebaixado à classe de vila. Somente em 1929 São Gonçalo restabelecida a premissa de cidade e sede do município. (ARAÚJO; MELO, 2014).

De acordo com Silva (2001), a composição do espaço urbano de São Gonçalo se corrobora com o início das práticas industriais e comerciais na qual se amplia no final do século XIX, sendo capaz de intitular de um primeiro ápice na produção do espaço urbano de São Gonçalo.

Em companhia da entrada de grandes indústrias, bem como: Fiat Lux e Cimento Portland, estimula-se a um processo de urbanização que se concebe por um lado pela atividade especifica das indústrias que, agregam o poder público da cidade com a finalidade que o munícipio efetue as operações de infraestrutura indispensáveis ao seu andamento ou, e algumas ocasiões, atua de modo direto nessas áreas de forma a facilitar a sua instalação. Em contrapartida, considera-se a ação dos loteadores, com a ampla expansão da população de São Gonçalo, onde se reúne com o crescimento vegetativo, a população migrante na qual chega com o intuito de trabalhar nos estabelecimentos e indústrias daquela que adquiria o apelido de "Manchester fluminense" Silva (2001), possuía consideráveis capacidades de ampliação do capital com a geração de loteamentos.

Com a ampla demanda imobiliária motivada pela abundância de trabalhadores para as indústrias e, com isso, a indispensabilidade de erguerem casas, vilas operarias, conjunto habitacional e toda infraestrutura para receber a população que só havia crescendo, as terras no campo de resquício sofreram o processo de loteamento nos anos de 1940, caracterizando um novo desenho e produzindo novos atributos a região conforme o crescimento da ocupação urbana. A construção da rodovia federal, denominada BR101, na qual possui um breve trecho percorrendo o município de São Gonçalo, possibilitou conexão de maneira mais expressa acerca dos bairros de São Gonçalo aos centros de Niterói e do Rio de Janeiro, expandindo o crescimento industrial e pontos populacionais, além disso, por quase toda extensão das bordas da rodovia e localidades mais longínquas e menos urbanizadas, ocupando futuramente a "nova periferia" (GUEDES, 1997).Assim, pode-se ressaltar a metáfora de Lefebvre (2001, p. 11) ao expor que "o tecido urbano não é apenas um tecido jogado sobre o território", em razão de que:

com efeito, o interesse do "tecido urbano" não se limita à sua morfologia. Ele é o suporte de um "modo de viver" mais ou menos intenso ou degradado: a sociedade urbana. Na base econômica do "tecido urbano" aparecem fenômenos de outra

ParaOnde!?, Porto Alegre, v.12 n.2, p.59-72, 2019.http://seer.ufrgs.br/paraonde Edição Especial - III Colóquio de Pesquisadores em Geografia Física Ensino de Geografia 
ordem, num outro nível, o da vida social e "cultural.

Em princípio, os elementos aludidos foram essenciais para impulsionar os grandes projetos econômicos inseridos no município de São Gonçalo, indispensáveis para a modificação da região.

Esse florescimento se dá de preferência por toda extensão do núcleo NevesAlcântara, visto que Neves se instala como um crucial eixo industrial de São Gonçalo, no mesmo tempo em que Alcântara se organiza como um decisivo centro comercial. É no decorrer desse eixo na qual se encaminhara a organização de zonas de atuação de loteamentos, constituindo uma extensa fração de loteamentos, pensado para atender a essa população operaria e varejista da cidade. Esse processo se fortalece extremamente nos anos 40 e 50, movendo uma abundante acumulação do capital no âmbito imobiliário, sendo composto por inúmeros loteamentos são realizados de maneira precária. Conforme Santos (1986) o ápice do retalhamento de terras com a intenção de loteamentos no município de São Gonçalo ocorre na década de 1950 onde aconteceram mais de 130 mil lotes.

Ainda de acordo com o autor, há uma lógica capitalista detrás do crescimento da metropolitana fundada em loteamentos populares- tal como o município de São Gonçalouma vez que a procura na qual essa categoria de residência contempla possui um grau de renda bastante baixo, decorrente disso, as empresas responsáveis pelo loteamento, propagam esse repartilhamento sem alguma melhoria urbanística. Dessa maneira, os empresários, premeditadamente desprezam as regulamentações do espaço urbano, gerando loteamentos sem as mínimas condições de infraestrutura, na qual fortemente por essa razão, obtém um digito de capital bastante curto, ficando alcançável para os proletariados com remunerações baixas que fazem o modelo de produção capitalista na metrópole mover-se.

No momento em que os habitantes vão para esses loteamentos confrontados por uma despesa social de alto nível para residirem nessas áreas (por exemplo: ausência de iluminação, condução, saneamento básico e entre outros serviços de utilidade pública) na qual opõe ao inferior consumo financeiro dos lotes (SANTOS 1986). Existe apesar disso a possibilidade- nem a todo o momento viabilizado- de retorno de dos custos, isto é, diminuição do custo social e a extensão da despesa financeira de habitar nesses loteamentos, a valorização dos equivalentes. Todavia essa valorização necessita movimentação dos moradores dos loteamentos adjacente ao poder público na tentativa de organizar um loteamento de infraestrutura básica.

Essa maneira de produção da cidade, embasada na logística de loteamentos abertos, inúmeras delas marcadas sem a menor condição de infraestrutura, ainda a rastro do tecido urbano da cidade na qual é descrito por um modelo de construção horizontal e pela e o acompanhamento de amplos números de domicílios em condições precárias.

Conforme o autor Geiger (1956, p. 61) identifica-se que "os precários serviços urbanos de São Gonçalo apresentam ao observador um contraste chocante com a riqueza da produção material do município". Este episódio, distanciada de retratar uma anomalia, ou resultado da ausência de planejamento, demostra as propriedades próprias do desenvolvimento do capitalismo nessa cidade, que se conduz a partir da acumulação de capital, na qual consegue não ser sublime, do ponto de vista social, contudo não deixar de ser uma organização espacial.

ParaOnde!?, Porto Alegre, v.12 n.2, p.59-72, 2019.http://seer.ufrgs.br/paraonde

Edição Especial - III Colóquio de Pesquisadores em Geografia Física Ensino de Geografia 
A respeito da indagação, anterior, a propósito, constantemente repetida, cujas problemáticas da cidade se dá decorrente a omissão de planejamento por parte do segmento público, encaixa mencionar a contribuição deLojckine, acerca do assunto:

Pode de fato acontecer que os agentes do poder de Estado não tenham nenhuma consciência da política urbana real que eles ajudam a por um funcionamento, embora a inconsciência e ausência de domínio dos processos de urbanização postos em funcionamento decorram a nosso ver, não de uma necessidade inelutável, mas de um tipo de sociedade histórica e geograficamente determinada (LOJCKINE, 1981, p. 181).

É capaz de admitir, a qual apesar de desempenhar a realidade dos países (ditos) "desenvolvidos", em particular a França, essa análise tem extensa competência de contribuir na compreensão da realidade gonçalense. Desse modo, essa provável desordenação é fruta da maneira de incorporação da cidade na lógica de reprodução do capital, seja por meio do capital imobiliário ou o capital industrial e podendo elucidar, no leste metropolitano fluminense na qual se declara como verdade inevitável, crescendo sua mancha metropolitana em direção a novos territórios.

Em outro instante não tão significativo- na composição do tecido urbano de São Gonçalo, ocorre entre a década de 1970 e 1990, onde passa preponderar a elaboração de loteamentos, em que existe a produção de lotes, de maneira abrangente em menor proporção, sem desmembramento, onde cada domiciliado é encarregado pela construção de sua domicílio. De uma maneira geral esses loteamentos estão posicionados nas mesmas zonas de lote abertos, isto é, em bairros periféricos do município de São Gonçalo.

No atual período, que possui enquanto base temporal, a partir da década de 1990, na qual é delimitada por meio da construção de condomínios e loteamentos fechados verticais e horizontais. Nesta parte da pesquisa determina-se enquanto condomínios fechados com base em dois princípios: propriedade coletiva da terra, isto é, falta de desmembramento do terreno; havendo de áreas de uso coletivo não público- bem como: ruas, praças, etc (SILVA, 2012). Esta recém-adquirida modelo de produção, pensado em uma extensa parcela, enquanto público-alvo, a classe média, ou média baixa, tem carregado amplas modificações no tecido urbano de São Gonçalo, sendo eles, um aumento do processo de verticalização em localidades que até então apresentavam uma horizontalidade.

No período de 1930 a 1945, as atividades industriais adquirem determinada proporção por meio dos produtos gerados no próprio território nacional, as conhecidas substituições das importações. O Estado se organiza e aponta as atividades econômicas, com extenso estímulo na indústria. Politicamente, a época era definida pela ditadura do Estado Novo, na era Vargas, formando um sistema político apoiado na Personalismo e Clientelismo, em particular grupos de poder efetuados pelas indicações e intervenções. São Gonçalo por expor áreas disponível, estar perto de ambas as capitais, até o momento, estado da Guanabara (Niterói) e o distrito federal (Rio de Janeiro), desperta investimentos produtivos, com forte presença da indústria.

Nos anos de 1945 a 1964 foi definido por conduta de movimentos sociais, acentuada presença sindical aceleração do processo industrial (Indústria de Base e Bens de Consumo Duráveis). A conveniência de infraestrutura leva ao reconhecimento de

ParaOnde!?, Porto Alegre, v.12 n.2, p.59-72, 2019.http://seer.ufrgs.br/paraonde Edição Especial - III Colóquio de Pesquisadores em Geografia Física Ensino de Geografia 
deficiências básicas, na qual deu brecha para ações políticas populistas e assistencialistas.

O capitalismo monopolista de Estado passa a torna-se símbolo do período de 1964 ao final dos anos de 1980, com o desenvolvimento das indústrias de bens de consumo duráveis e as restrições às importações.Nesse sentido, São Gonçalo perpassa por um processo de esvaziamento industrial, em virtude da disputa com outros municípios brasileiros, sobretudo, os municípios do estado de São Paulo. O deslocamento da capital do país, para o centro oeste (Brasília), e a unificação do estado da Guanabara e do Rio de Janeiro cooperaram para o desaquecimento da economia local.

Os aspectos políticos procederam de maneira mais tenebrosa com a instalação dor regime ditatorial civil-militar, a repressão dos direitos individuais, a coibição do associativismo e a punição aos movimentos sociais marcaram duro poder autoritário do Estado. Conforme afirma que: "A limitação partidária (apenas dois partidos) monopolizou os anseios da população, o desemprego, o endividamento (externo e interno) e a inflação muito elevada contribuíram para a caracterização da década 1980 como perdida." (SILVA; D’ ÁVILA, 2015, v.1, p.173-197).

As deliberações do capitalismo de caráter de monopólio na qual se instaura em escala global, o capitalismo financeiro passa a articular as normas do padrão de acúmulo dos anos de 1990 até a atualidade. Estas regras são acompanhadas de mecanismos privados, de feitio hegemônico, com a evidente compreensão na qual necessitam atuar no sentido de admissão aos outras frações da sociedade. O poder midiático disseminação objetos geográficos de caráter global, bem como: o Shopping, entre outros, indicam a robustez desse grupo hegemônico e sua eficácia de persuasão.

No âmago desse processo, verifica-se a multiplicação de condomínios fechados na centralidade urbana de São Gonçalo, na qual é composta principalmente de duas maneiras: a começar de Neves, Centro e Alcântara, e dois centro organizados nesse eixo, sendo eles: o centro principal da cidade, que esta localizada a sede dos poderes públicos da cidade, e o centro de Alcântara, crucial núcleo de serviços e comercio da cidade de São Gonçalo e vizinhas.

O lugar expõe a extensão das coisas que ocorrem no espaço. Esta dimensão esta associada ao local de escala da construção social, a influencia dos bairros, da cidade, da região e do mundo na qual vai variando a maneira de refletir acerca da vida, em seu uso, consumo, apoderamento da construção do espaço em distintas redes de fluxos de lugares. Santos (2002, p.48) aponta a relevância de se compreender o lugar, pois para o autor: "é o lugar que atribui às técnicas o principio de realidade histórica, relativizando seu uso, integrando-os num conjunto de vida, retirando-as de sua abstração empírica e lhe atribuindo efetividade histórica".

Sendo assim, a escola possui relações sociais, técnicas e pedagógica forçada por uma circunstancia nas quais alteraram a forma do lugar, em elencar a construção do saber através do tempo. Nesse sentido, pensar a localidade da escola, é ponderar a respeito das inúmeras possibilidades e acontecimentos na qual influenciam as instituições de ensino a serem singular em virtude da maneira de seu desenvolvimento e a forma estar situada na localidade. Quando se pensa nas localizações das escolas, pode-se notar como são as condições dos alunos que estão introduzidos nela.

Assim, é imprescindível destacar os aspectos físicos e sociais da paisagem da

ParaOnde!?, Porto Alegre, v.12 n.2, p.59-72, 2019.http://seer.ufrgs.br/paraonde

Edição Especial - III Colóquio de Pesquisadores em Geografia Física Ensino de Geografia 
escola analisada. A começar pelo clima, na qual é na categoria tropical atlântico - por causa do município de São Gonçalo esta localizada no fundo da Baia de Guanabaracaracterizada com chuvas de verão e inverno, contudo, parcialmente seco. E a topografia retrata enquanto indispensáveis acontecimentos geográficos, ilhas localizadas até os limites das léguas municipais, tais como: A ilha do Engenho, posicionada no distrito de Neves, a ilha do Tavares, a ilha do Carvalho, ilha das Flores (decorrente a criação da BR101, e devido ser uma base dos fuzileiros navais, acabou ocorrendo aterramento e virando uma península), ilha de Itaoca (inúmeros morados associam ao antigo lixão desativado- decorrente da construção de uma via expressa para a COMPERJ- contudo, a ilha se localiza um pouco distante de onde era realmente o lixão), ilha do Pontal e Ananás. Além disso, dispões de uma ampla rede hidrográfica, porém, lamentavelmente, em sua totalidade os rios da cidade padecem de violento processo de assoreamento e, também, abrigando extensa carga de dejetos de esgoto domésticos.

O relevo de São Gonçalo indica três variedades: morros isolados, serra e planície. Os morros estão dispersos nas orientações de sul a oeste do município.

Enquanto as regiões de planícies estão localizadas quase inteiras na região norte do município, como aponta a figura acima, próxima do limite de Itaboraí.

A exuberância das pretéritas colônias não mais permanece na rugosidade da paisagem, a ocupação da humanidade acabou destruindo toda a vegetação natural para a instalação da cultura agrícola colonial (laranja e limão). A vegetação característica do município é mangue e arbustiva típica de planície. Em localidades na qual padecem com as inundações, no período de precipitação, a vegetação é rasteira. Ainda possuindo pequenas áreas com bioma de cerrado e gramíneos que ocupam cerca de $20 \mathrm{~km}$.

\section{Metodologia}

$\mathrm{Na}$ pesquisa fez-se uso da abordagem qualitativa na qual esta interessada no modo como os diferentes sujeitos dão sentido às suas vidas e estão comumente a questionar os sujeitos da investigação e como interpretam as suas experiências e o modo como estruturam o mundo social em que vivem (BOGDAN; BIKLEN, 1994).

A pesquisa qualitativa tem como objetivo a qualidade e não é inferida por números, a ideia é compreender ou interpretar uma dada realidade do indivíduo. No nosso caso, buscamos entender as representações dos estudantes em um determinado grupo, realidade, e a partir disso, interpretar como é a percepção sobre um determinado lugar. A ideia é dinamizara compreensão da realidade pelo indivíduo.

Sendo atividade produzida no CIEP 041- Vital Brazil, localizado no bairro do Luiz Caçador, em São Gonçalo/RJ, na turma do $6^{\circ}$ ano do ensino fundamental (turno da manhã).

\section{Manual de instrução do jogo}

1. Construir o esqueleto do jogo da velha;

2. Sendo posto em cada espaço uma letra em ordem alfabética;

3. Produzir nove questões a respeito do assunto selecionado;

ParaOnde!?, Porto Alegre, v.12 n.2, p.59-72, 2019.http://seer.ufrgs.br/paraonde

Edição Especial - III Colóquio de Pesquisadores em Geografia Física Ensino de Geografia 
4. Distribuir a turma em duas equipes $(\mathrm{X} / \mathrm{O})$;

5. O time selecionara uma letra e respondera ao questionamento. Em situação de acerto assinalar a insígnia da equipe e no caso de erro marcar o ícone do grupo adversário.

\section{Perguntas}

a) A passagem de uma frente mudou o tempo em São Gonçalo. Sabemos que essa frente tem origem próxima aos pólos e devido ao vento chegam até nossa cidade provocando baixa temperatura. Visto isso, que tipo de massa é essa?

b) São Gonçalo tem característica, assim como quase a metade do Brasil, de um clima tropical. As massas de ar que nascem nessas regiões tropicais provocam temperaturas bastante elevadas. Como é chamada essa massa de ar?

c) A praia das pedrinhas, localizada no litoral de São Gonçalo, banhado pela Baia de Guanabara, sendo um dos pontos turísticos da cidade. Sabendo que a Baia de Guanabara é banhada pelo oceano Atlântico, responda: Qual tipo de massa de ar se origina em áreas oceânicas, como a praia das pedrinhas, de onde recebe umidade provocando chuva no deslocamento de sua massa de ar?

d) São Gonçalo está localizada no fundo da Baia de Guanabara, sendo assim a caracterizando como uma região litorânea. Assim, a cidade envolve uma massa de ar na qual nasce no interior do continente dando em períodos sem chuva e seca. Qual o nome dessa massa que não caracteriza nossa cidade?

e) Quando em constantes deslocamentos, a massa de ar encontra-se com outras tem o nome de?

f) A frente mais comum em São Gonçalo é?

g) Qual é a massa de ar fria que provoca recuo de massa de ar quente, ocasionando queda nas temperaturas?

h) A massa de ar tropical faz a massa de ar frio recuar, ocasionando elevação nas temperaturas do ar atmosférico?

i) O Brasil é atingido por cinco massas de ar. Quais são elas?

Ganha o time na qual construir primeiro a sequência de três símbolos, sejam eles na horizontal, vertical e transversal.

\section{Resultados e discussão}

Partindo da alegação de que a utilização de atividades lúdicas opera enquanto mecanismo favorável ao processo de ensino/aprendizagem, procurou no CIEP 041-Vital

ParaOnde!?, Porto Alegre, v.12 n.2, p.59-72, 2019.http://seer.ufrgs.br/paraonde Edição Especial - III Colóquio de Pesquisadores em Geografia Física Ensino de Geografia 
Brazil (localizado no bairro Luiz Caçador, SG/RJ) com os alunos do 6을 ano do ensino fundamental utilizá-la como artificio para estimular a procura pelo conhecimento, sendo nesse caso o conteúdo de climatologia. A atividade com jogos é relevante não só colaborar a relação entre os alunos, mas, também, para amparar as indagações cujas são julgadas mais complicadas.

Sendo também o estudo a respeito da climatologia dispõe de ampla relevância visto que contribui no esclarecimento de abundantes fenômenos cotidianos observado pelo discente. Conforme elucida Callai (2006) os espaços cotidianos jamais devem ser esquecidos nas aulas de Geografia, estes precisam ser retomados e reinterpretados, criando possibilidades de pensar em contextos mais amplos. Nesse sentido a cidade é estruturante para a relação com os espaços vividos, tendo em vista que a cidade para Cavalcanti (2007, p. 93), é:

[...] uma expressão da complexidade e da diversidade da experiência dos diferentes grupos que a habitam. Seu arranjo vai sendo produzido para que cada habitante possa viver o cotidiano, compartilhando desejos, necessidades, problemas com os outros habitantes. Ela é, nesse sentido, espaço da vida coletiva, espaço público.

Dessa forma, incorporar a cidade no pensamento escolar auxilia para que os educandos entenderem as relações seus espaços de vivencia, juntamente com seu direto, principalmente o direito a cidade, e em sua formação social, enquanto cidadão crítico.

O jogo da velha apresentou peculiaridade excitante e produtiva em seu desenvolvimento dado que alunos participam de sua aquisição. Foi produzido um sentimento de disputa, obediência e coleguismo, em razão de quão grande é a atividade lúdica se torna soberano o entusiasmo.

Dessa forma, atividade trouxe suas formas diferentes de analisar uma construção de conhecimento, gerando neles o interesse na aprendizagem do conteúdo. Assim, "o jogo vem como um estímulo tanto para melhor a compreensão do conteúdo, quanto para o crescimento e o desenvolvimento intelectual do aluno - fundamental, também, para atingir a responsabilidade e a maturidade" (VERRI; ENDLICH, 2009, p.02).

Nesse sentido, constitui-se em considerar a proposta de uma atividade na qual eles sejam capazes absorver o tema de forma recreativa e prazeroso, com o propósito de colaborar na aprendizagem determinados assuntos. Desse modo, é fundamental partir da realidade local do discente, contudo, construir junções com outras escalas de analise com o intuito de melhorar o processo de ensino/aprendizagem.

Com base nisso, os discentes apresentaram domínio sobreas características climáticas de sua cidade, o mais surpreendente que utilizaram de conteúdos para além do esperado; sendo a respeito de maritimidade e continentalidade, na qual o conteúdo está vinculado com a dinâmica climatológica, porém o objetivo do jogo era somente deter domínio a respeito do tipo de clima vigente na cidade de São Gonçalo e as massas de ar que influencia o município e o país.

Vale ressaltar, também, o amplo conhecimento dos estudantes a respeito do assunto sociedade e natureza. Visto que apresentaram propriedade para abordar de como as ações dos seres humanos vem interferindo na dinâmica climática da Terra e de São Gonçalo, utilizaram-se do conceito de aquecimento global para embasar seus

ParaOnde!?, Porto Alegre, v.12 n.2, p.59-72, 2019.http://seer.ufrgs.br/paraonde Edição Especial - III Colóquio de Pesquisadores em Geografia Física Ensino de Geografia 
argumentos. Além disso, associaram o intenso calor que faz no centro da cidade decorrente da formação de uma ilha de calor, já que apresenta prédios de grande porte e um afastamento exorbitante do litoral da baia de Guanabara.

Assim, torna se claro que a colaboração atividades lúdicas é bastante significativo enquanto recurso no processo de ensino/aprendizagem, em virtude que instaura um entusiasmo por grande parte dos alunos. O jogo é um instrumento que expande incontáveis princípios, bem como: sociabilidade e obediência. Desse modo, no transcorrer da atividade percebemos uma maior relação e um melhor desempenho na matéria.

\section{Considerações finais}

Uma das grandes dificuldades do docente de Geografia dispõe de estimular os estudantes a aguçar seus conhecimentos a respeito de sua cidade, mas também do mundo em que vive. Além disso, o que se tem apurados nas escolas cotidianamente são problemas que o magistério esbarra, como: a precariedade de recursos da escola e a imposição da obrigatoriedade do livro didático aparecer em sala de aula. Tendo enquanto resultado, aulas exaustivas fundamentado na hipótese de que os professores são possuidores do saber e os alunos são receptáculos do conhecimento.

O intuito da elaboração dessa ferramenta (o jogo) enquanto um recurso didático conduz em convergência ao presente momento do ensino de geografia, na qual é abranger a aplicação uma metodologia diferenciada onde considera a presença do discente de maneira atuante.

Perante o mostrado, constata se que o jogo é um significativo material didático de incentivo para o ensino/aprendizagem da Geografia colaborando na eficácia de conceber alguns conceitos e conteúdos geográficos, além do senso coletivo e do pensamento crítico.

\section{Referências}

ARAÚJO, Victor; MELO, Hildete. O processo de esvaziamento industrial em São Gonçalo no século XX: auge e declínio da "Manchester Fluminense". Cadernos do desenvolvimento Fluminense, № 4, pp. 65-87, 2014

BARBOSA, Magno Emerson; OLIVEIRA, Adriana. Climatologia e internet: análise e proposta metodológica para o ensino de geografia no ensino médio. Revista geonorte, $\mathrm{v}$. 1, p. 108-120, 2012.

BERTRAND, Gorges. Paisagem e geografia física global: esboço metodológico. Caderno de Ciências da Terra, n. 13, p. 1-27, 1971.

CALLAI, Helena Copetti. A formação do profissional da Geografia. 2. a ed. ljuí (RS): Unijuí, 2006.

CAVALCANTI, Lana de Souza. 0 ensino de Geografia na escola. São Paulo: Papirus, 2012.

CAVALCANTI, Lana de Souza. Cidade e vida urbana: a dinâmica do/no espaço intraurbano e a formação para a participação em sua gestão. In: , Lana de Souza. PAULA, Flávia Maria de Assis. (Orgs.). A cidade e seus lugares. Goiânia: Vieira, 2007, p. 10-28.

GEIGGER, Pedro Pinchas. Urbanização e industrialização na orla oriental da Baía de Guanabara. Revista Brasileira de Geografia, Rio de Janeiro, out/dez 1956. Pag.; 61

ParaOnde!?, Porto Alegre, v.12 n.2, p.59-72, 2019.http://seer.ufrgs.br/paraonde Edição Especial - III Colóquio de Pesquisadores em Geografia Física Ensino de Geografia 
LOJKINE, Jean. 1981. O Estado capitalista e a questão urbana. São Paulo : Martins Fontes

MODESTO; Nilo Sergio D' avila, Agentes, Hegemonia e Poder na Produção do Espaço.

2015, v.1, p.173-197.

SACRAMENTO, Ana Claudia Ramos; CAMPOS, Aline Mello; CARVALHO, Fabiana Sanchez; SILVA, Jupiara de. Jesus. Educação Geográfica e o Estudo da Cidade e do Urbano em São Gonçalo - RJ: atividades de aprendizagem dos docentes e discentes. Revista Tamoios (Online), v. 12, p. 84-100, 2016.

SACRAMENTO, Ana Claudia Ramos; SOUZA, Camila Viana. A produção social do espaço e o ensino da cidade de São Gonçalo. Revista GeoUECE, v. 5, p. 6-32, 2016.

SANTOS, Milton. Como você conceitua as noções de urbanização e metropolização (entrevista). Revista Caramelo,São Paulo, n.7, p. 60-71, 1994.

SANTOS. Milton. A natureza do espaço. Técnica e tempo. Razão e emoção.São Paulo: Edusp, 2002

SILVA, Luciana. Gonçalves. Jogos e situações-problema na construção das noções de lateralidade, referências e localização espacial. In: CASTELLAR, Sonia. Educação geográfica: teorias e práticas docentes. São Paulo: Editora Contexto, 2006, p. 137-156. VERRI, Juliana Bertolino; ENDLICH, Ângela Maria. A utilização de jogos aplicados no ensino de geografia. Maringá, Revista Percurso - NEMO, 2009 v. 1, n. 1, p. 65-83.

SILVA, Cledir Ribeiro da.O declínio industrial gonçalense. Trabalho de conclusão de curso: FFP-UERJ:São Gonçalo, 2001.

SILVA, Oséias Teixeira da.Centralidade e produção do espaço urbano em Alcântara São Gonçalo (RJ). Rio de Janeiro: UFRJ/PPGG, 2012.

SILVA, Cledir Ribeiro da.O declínio industrial gonçalense. Trabalho de conclusão de curso: FFP-UERJ:São Gonçalo, 2001.

SILVA, Oséias Teixeira da.Centralidade e produção do espaço urbano em Alcântara São Gonçalo (RJ). Rio de Janeiro: UFRJ/PPGG, 2012. 